\title{
Trait- and size-based descriptions of trophic links in freshwater food webs: current status and perspectives
}

\author{
David S. BOUKAL ${ }^{1,2^{*}}$ \\ ${ }^{1}$ University of South Bohemia, Faculty of Science, Department of Ecosystems Biology, České Budějovice; ${ }^{2}$ Biology Centre AS CR, \\ vvi, Institute of Entomology, Laboratory of Aquatic Insects and Relict Ecosystems, České Budějovice, Czech Republic \\ *Corresponding author: boukal@entu.cas.cz
}

\begin{abstract}
Biotic interactions in aquatic communities are dominated by predation, and the distribution of trophic link strengths in aquatic food webs crucially impacts their dynamics and stability. Although individual body size explains a large proportion of variation in trophic link strengths in aquatic habitats, current predominately body size-based views can gain additional realism by incorporating further traits. Functional traits that potentially affect the strength of trophic links can be classified into three groups: i) body size, ii) traits that identify the spatiotemporal overlap between the predators and their prey, and iii) predator foraging and prey vulnerability traits, which are readily available for many taxa. Relationship between these trait groups and trophic link strength may be further modified by population densities, habitat complexity, temperature and other abiotic factors. I propose here that this broader multi-trait framework can utilize concepts, ideas and existing data from research on metabolic ecology, ecomorphology, animal personalities and role of habitats in community structuring. The framework can be used to investigate non-additive effects of traits on trophic interactions, shed more light on the structuring of local food webs and evaluate the merits of taxonomic and functional group approaches in the description of predator-prey interactions. Development of trait-and size-based descriptions of food webs could be particularly fruitful in limnology given the relative paucity of well resolved datasets in standing waters.
\end{abstract}

Key words: predator-prey interactions, body size, foraging, vulnerability, habitats, spatiotemporal distribution.

Received: June 2013. Accepted: October 2013.

\section{INTRODUCTION}

Trophic links characterize energy flow and describe how individuals, populations and species interact in food webs. Their non-random, structured patterning begets stability and persistence of complex communities (Yodzis, 1981; De Ruiter et al., 1996; Neutel and Heesterbeek, 2002), underlies ecosystem functioning (Brose et al., 2012) and mediates the impact of human disturbance including climate change (Dossena et al., 2012; Lurgi et al., 2012) and commercial fisheries (Frank et al., 2005; Garcia et al., 2012). In marine and freshwater ecosystems, feeding links are thought to dominate over other biotic interactions, such as mutualism or competition for space (Woodward, 2009). Knowledge of the factors that determine the presence and strength of trophic links is therefore crucial for our understanding of food webs and community dynamics in aquatic habitats. Various metrics of interaction strengths in food webs exist (Berlow et al., 2004). This paper focuses on quantitative descriptors of individual trophic links: predation rates and prey selectivity.

Building upon the seminal works of Kleiber (1932) and Peters (1983), body size is used to describe predator-prey interactions (Brose et al., 2006; Petchey and Dunne, 2012) as well as other properties of individuals, populations and communities (Brown et al., 2004; Woodward and Warren,
2007; Sibly et al., 2012). Body size underpins biomass growth and energy transfer in aquatic habitats (Edgar, 1990) and size-based metrics describe well the structure and function of entire aquatic ecosystems (Hildrew et al., 2007; Rudolf and Rasmussen, 2013). Community size spectra are also sensitive to natural and human-driven disturbances (Brucet et al., 2005; Solimini et al., 2005; Emmrich et al., 2011) and can be used in environmental monitoring (Basset et al., 2012; Garcia et al., 2012).

Size-based views are thus particularly prominent in aquatic ecology and studies of freshwater food webs generated some of the most detailed datasets elucidating the role of body size in community structuring (Woodward and Hildrew, 2002). Most data, however, come from running waters (Gilljam et al., 2011). Food webs in standing waters remain less studied (Woodward et al., 2005) and we currently rely on a limited body of direct, sufficiently detailed evidence of their topology and the distribution of trophic link strengths. In one of the first studies, Havens (1992) analysed the connectance of pelagic food webs in 50 small lakes and ponds in New York state; his cumulative web approach combined field surveys of species composition with information on their diet gleaned from the literature, which omitted potential variation between habitats and trophic link strengths. Few datasets have been 
added since then. Recent meta-analysis of scaling of food web properties with diversity and complexity across ecosystems (Rall et al., 2010) included data from 16 standing freshwaters: the 11 largest New York state lakes, a compilation of food webs in oligotrophic Sierra lakes (Harper et al., 2005), the pelagic community of Tuesday lake (Jonsson et al., 2005), and the small and fishless Skipwidth Pond food web (Warren, 1989). Only the last three datasets provide direct evidence (stomach contents or laboratory observations) to document trophic interactions in the food web, and even they focus only on metazoans and do not report trophic link strengths.

Moreover, there is clearly room for multivariate descriptions of food webs and validation of existing theory (Osenberg and Mittelbach, 1989; Hildrew et al., 2007; Montagnes et al., 2008; Petchey et al., 2008; Ings et al., 2009; Rossberg et al., 2009; Jacob et al., 2011) despite the enormous success of purely size-based studies in aquatic ecology. Even if we could define a single abstract feeding niche to characterize trophic links in a food web, body size may not correlate strongly with the niche parameters (Williams et al., 2010). Moreover, multidimensional niches requiring additional traits can describe the topology of empirical food webs with higher likelihood than one-dimensional niche models, including those based on body size (Alessina et al., 2008; Rohr et al., 2010; Williams and Purves, 2011; Eklöf et al., 2013). In less abstract terms, the presence and strengths of trophic links are affected by temperature (Henri et al., 2012; Rall et al., 2012), species identity (Nakazawa et al., 2011, Gilljam et al., 2011; Rall et al., 2011), evolutionary history (Bersier and Kehrli, 2008), and predator and prey traits more mechanistically tied to the predation process (Winemiller, 1991; Wirtz, 2012; Klecka and Boukal, 2013). These traits can relate to life history, behaviour, morphology, and habitat preferences.

Multivariate trait characteristics are indeed common in ecological analyses. Functional group definitions used to characterize the main axes of variation in community assembly and ecosystem functioning often include multiple traits (McGill et al., 2006; Messier et al., 2010). Functional groups are also employed to predict responses to environmental perturbations in various taxa including plant communities (Suding et al., 2008), phytoplankton (Litchman et al., 2007) and stream macroinvertebrates (Poff et al., 2006). We could hence envisage that a cohort-based approach focusing on body size, major food type and a few other traits could satisfactorily model the structure and dynamics of whole food webs or even the entire Earth biota (Purves et al., 2013). In order to achieve such ambitious goals, the critical question lies in identifying the functional traits that correlate most with the strengths of trophic links.

This paper aims to summarize current knowledge and data on traits used in characterization of trophic link strengths in standing waters and other aquatic habitats. It is not an exhaustive review; its purpose is to provide an empirical and theoretical background for multi-trait descriptions of food web interactions and identify promising areas of research for freshwater ecologists and limnologists. It begins with an overview of individual-level processes and biotic/abiotic factors underlying predation pressure (Predation as a process). I then outline, the description of the multi-trait framework that can be used to link individual traits to trophic interaction strengths, including a brief summary of a recently published working example (Klecka and Boukal, 2013). The third to sixth subheadings below deal with the main trait groups used in the framework. The two subheadings on Multi-trait food webs below subheadings focus on body size allometries of traits that affect predation strength and on interactions between these traits. Although the focus is primarily on standing waters, the proposed framework can also be applied to other aquatic habitats.

\section{TRAIT- AND SIZE-BASED DESCRIPTIONS OF TROPHIC LINKS}

\section{Predation as a process}

The process of predation that ultimately determines trophic link strength can be viewed from either predator or prey perspective. For predators, the entire process can be divided into four main stages: encounter with prey, attack, handling (ingestion), and digestion (Jürgens and Matz, 2002; Montagnes et al., 2008). From the prey perspective, the main stages include encounter, escape from attack and escape after being caught by the predator (Greene, 1983).

Habitat structure, abiotic properties, spatial scales and predator and prey population densities can modify the importance of each of these steps. Aquatic environments differ from terrestrial habitats in the viscosity of the surrounding medium and by the strong differences between structurally simple pelagic habitat and more complex benthic habitats and littoral zones. Water viscosity affects the energetics of movement differently in small and large individuals (Müller et al., 2000) and viscous forces creating drag are much more important for protozoans and small zooplankton than for fish (Yates, 1986). For example, small-scale turbulences can both increase and decrease feeding rates of the copepod Acartia tonsa Dana by increasing its encounter rate with prey or by disrupting its feeding current (Saiz and Kiørboe, 1995); both mechanisms have little or no impact on feeding rates of fish and large invertebrates. Structural complexity of macrophyte stands and bottom debris makes prey detection more difficult and provides refuges for prey (Gotceitas and Colgan, 1989), which in turn do not have to outrun their predators, while defensive strategies of prey that occupy open water must rely on rapid escape abilities or on minimizing the overlap with predators in space and time by shifted phenologies and diel migration patterns (Williamson, 1993). This means that size allometries of 
ecological phenomena are likely to differ in the different parts of the habitat (see section Predation in space and time: the importance of ST traits) and that the patterns of predation in standing freshwaters may differ from the much better studied running waters.

\section{Linking interaction strength to traits}

Many phenotypic traits of predators and their prey have been investigated in experimental studies and metaanalyses of predation. I divide traits that affect the strength of trophic links into three main groups (Fig. 1):

i) body size, measured as total body mass (Brose et al., 2006) or in other relevant units, e.g. the equivalent sphere diameter (Wirtz, 2012);

ii) traits that identify the spatiotemporal overlap between the predators and their prey (abbreviated as ST traits), e.g. the density risk (Williamson, 1993),

iii) predator foraging and prey vulnerability traits (abbreviated as FV traits).

Body size is a continuous trait; ST and FV traits can involve both continuous and discrete traits. I single out body size because it almost always affects predation intensity and because most recent literature on food webs focuses primarily or solely on body size. ST traits can be, but do not have to be, described jointly for both predators and prey (Fig. 1b) but FV traits are inherently different in predators and their prey. Almost any individual can become both predator and prey, but the traits that determine predator's potential prey range are bound to be different from the traits that make it more or less vulnerable to other predators. Predator foraging and prey vulnerability traits often interact (Williamson, 1993; Lundvall et al., 1999). FV traits can be thus understood as a lock-and-key mechanism (Fig. 1c): foraging traits are keys that allow the predator to open locks, i.e., successfully find and capture prey, even if some keys may be superior at opening most locks and some locks may resist almost any key. The relationship between traits and interaction strength can take any shape. A recently proposed approach relates the log-transformed predation rate $m_{i j}$ of predator $i$ feeding on prey $j$, to the vector of predator and prey phenotypic traits $\mathrm{v}$ trough a quadratic polynomial (Rossberg et al., 2009) as:

$\ln \left(m_{i j}\right)=\ln \left(a_{0}\right)+\mathbf{b}^{\mathrm{T}} \mathbf{v}+\frac{1}{2} \mathbf{v}^{\mathrm{T}} C \mathbf{v}$

with a positive scalar $a_{0}$, vector $\mathrm{b}$ and a symmetric interaction matrix $C$. This choice provides the simplest functional form that can describe increasing, decreasing and unimodal dependence of trophic link strength on the individual traits (Rossberg et al., 2009) and second-order (statistical) interactions between the traits. It covers many earlier models of interaction strengths as special cases, including food web models that consider variable trophic link strengths (Drossel et al., 2001; Loeuille and Loreau,
2005) and the classical niche model that describes food web topology as binary links (Williams and Martinez, 2000). The implicit assumption of constant consumption rate in equation (1) does not consider prey response and non-linear or frequency-dependent predation rates. Other measures of trophic link strength such as the attack rate or handling time could be used in equation (1).

a.

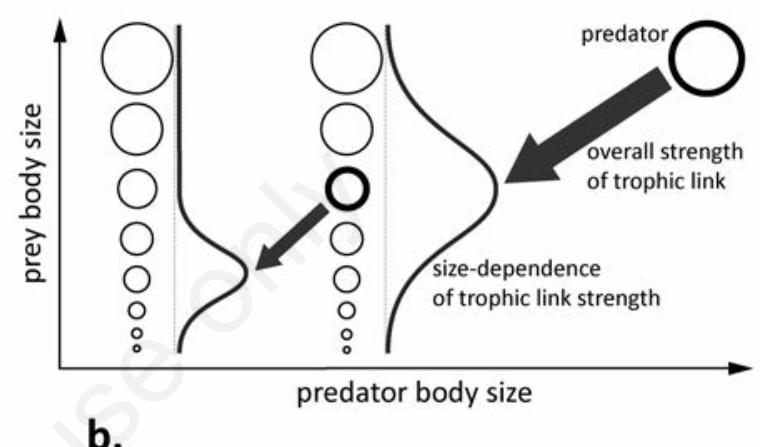

b.

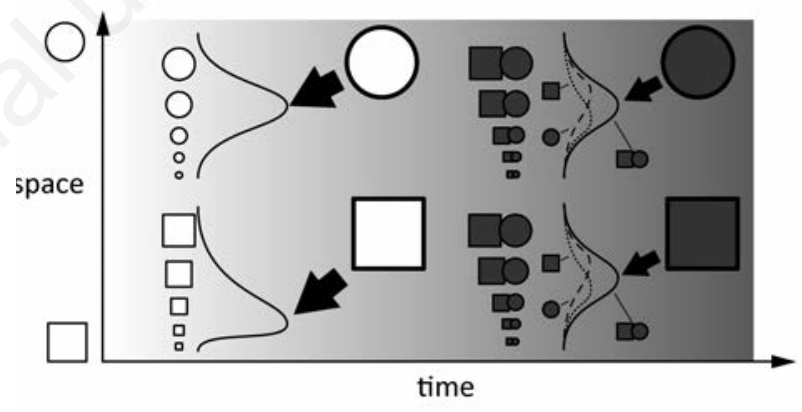

c.

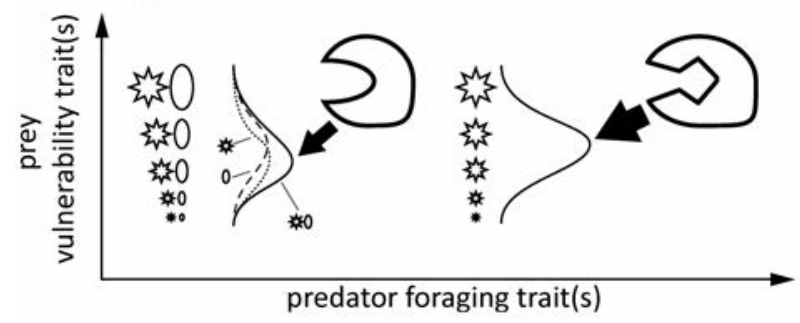

Fig. 1. Size dependence of trophic link strength in aquatic food webs and possible interactions between body size (proportional to symbol size) and ST and FV traits. Arrows connect predators (symbols with thick outline) to their prey (symbols with thin outline); arrow size shows the rate of energy flux characterizing overall strength of the trophic link. Bell-shaped curves illustrate the size dependence of trophic links. Larger predators eat more and consume larger prey (a). This pattern can be modified by predator and prey ST traits (b) and by FV traits (c). Example in (b): food web during the day (white-filled symbols) and at night (dark-filled symbols) in the benthic (squares) and pelagic (circles) habitat; benthic and pelagic prey mix at night. Example in (c): predators with unspecialized (left) and specialized (right) feeding mode foraging on undefended (ellipses) and defended (stars) prey. See text for details. 
The standard approach (Rossberg et al., 2009; Klecka and Boukal, 2013) of fitting parameters of equation (1) to the interaction matrix elements $m_{i j}$ is to assume independent, normally distributed errors and use nonlinear regression to minimize the sum

$\sum_{i, j}\left(m_{i j}-a_{0} \exp \left(\mathbf{b}^{\mathrm{T}} \mathbf{v}+\frac{1}{2} \mathbf{v}^{\mathrm{T}} C \mathbf{v}\right)\right)^{2}$

Predators and prey may differ in the number of relevant $\mathrm{ST}$ and FV traits. The $n$-dimensional $(n=2+p+q+\tilde{p}+\tilde{q})$ vector of predator and prey traits $\mathrm{v}, n$-dimensional vector $\mathrm{b}$ and n-by-n matrix in model (1) can be written as

$\mathbf{v}=\left(w, \tilde{w}\left|v_{1}^{\mathrm{ST}}, \ldots, v_{p}^{\mathrm{ST}}, \tilde{v}_{1}^{\mathrm{ST}}, \ldots, \tilde{v}_{\tilde{p}}^{\mathrm{ST}}\right| v_{1}^{\mathrm{FV}}, \ldots, v_{q}^{\mathrm{FV}}, \tilde{v}_{1}^{\mathrm{FV}}, \ldots, \tilde{v}_{\tilde{q}}^{\mathrm{FV}}\right)$

$\mathbf{b}=\left(b_{w}, b_{\tilde{w}}\left|b_{1}^{\mathrm{ST}}, \ldots, b_{p}^{\mathrm{ST}}, \tilde{b}_{1}^{\mathrm{ST}}, \ldots, \tilde{b}_{\tilde{p}}^{\mathrm{ST}}\right| b_{1}^{\mathrm{FV}}, \ldots, b_{q}^{\mathrm{FV}}, \tilde{b}_{1}^{\mathrm{FV}}, \ldots, \tilde{b}_{\tilde{q}}^{\mathrm{FV}}\right)$

and

$C=\left(\begin{array}{lll}C_{11} & C_{12}^{\mathrm{T}} & C_{13}^{\mathrm{T}} \\ C_{12} & C_{22} & C_{23}^{\mathrm{T}} \\ C_{13} & C_{23} & C_{33}\end{array}\right)$

where $w$ and $\tilde{w}$ are predator and prey body size, respectively (usually given as log-transformed body mass to reflect the underlying allometries), $v_{n}^{G}\left(\tilde{v}_{n}^{G}\right)$ are predator (prey) traits in trait group $\mathrm{G}$ (with $\mathrm{G}=\mathrm{ST}$ or FV), $p$ and $q$ are the respective numbers of ST and FV traits in predators, $\tilde{p}$ and $\tilde{q}$ the respective numbers of these traits in prey, and the different trait groups are emphasized by vertical lines in vectors $\mathbf{v}$ and $\mathbf{b}$ and blocks $C_{k l}$ in matrix $C$.

\section{Size-dependent foraging}

Larger predators generally have higher feeding rates than smaller ones (Fig. 1a), due to prey encounter rates increasing and handling times decreasing with predator body mass (Persson et al., 1998; Woodward and Warren, 2007). Larger predators also generally eat larger prey; this holds across taxonomic groups and ecosystems (Peters, 1983; Cohen et al., 1993; Brose et al., 2006). Size-dependent predation including cannibalism is ubiquitous in standing freshwater communities: it has been documented in protozoans (Simek and Chrzanowski, 1992; Montagnes et al., 2008), cladocerans (Langenheder and Jürgens, 2001), predatory aquatic insects (Wissinger, 1988; Rudolf and Armstrong, 2008; Klecka and Boukal, 2013) and fish (Wahlström et al., 2000; De Roos et al., 2003). Aquatic predators typically have 10-100 times larger body mass than their prey (Brose et al., 2006; Barnes et al., 2010; Klecka and Boukal, 2013). Most predators are inefficient at capturing or handling large or very small prey, or such prey may be unprofitable. This leads to a hump-shaped scaling of trophic link strength with the predator-prey mass ratio (PPMR; Brose, 2010; Fig. 1a).

Definitions of PPMR differ in scales at which the underlying data are grouped. The commonness of ontogenetic diet shifts in freshwater taxa (Werner and Gilliam, 1984; Miller and Rudolf, 2011) implies that individualpredator PPMR (mass of individual predator divided by the mean mass of all consumed prey individuals) and individual-link PPMR describing separately each predation event provide more accurate description of the food web structure than species- and link-averaged PPMRs (Gilljam et al., 2011, Nakazawa et al., 2011). The latter two types of PPMRs are easily collected for many taxa but gloss over individual-level variation, which can be substantial (Barnes et al., 2010). Values of individual-level PPRMs may differ from species-level PPMRs due to averaging and sampling effects (Woodward and Warren, 2007, Gilljam et al., 2011, Nakazawa et al., 2011). For the sake of comparability and due to the common ontogenetic shifts in traits, use of individual-level data is equally preferable for ST and FV traits treated below. More widespread use of individual-level data is nevertheless hampered by their unavailability for many groups and ecosystems including standing freshwaters, and the large amount of labour required to fill the gaps.

\section{Predation in space and time: the importance of ST traits}

ST traits characterize where and when individuals occur in a given habitat (Fig. 1b). They can cover (micro)habitat use, seasonal phenology and diurnal cycles. Standing freshwater bodies range in diameter from a few centimetres in lithotelms, dendrotelms and interstitial spaces to tens or hundreds of kilometres in large lakes, and their depth varies from a fraction of a millimetre to more than a kilometre. This varied morphology has profound effect on the biotic community and trophic interactions (Wellborn et al., 1996). ST traits should at least distinguish between organisms that occupy water surface (neustonic habitat), water column (pelagic/nektonic habitat) and bottom (benthic habitat). These three environments usually host very different communities and differ in trophic interactions (Warren, 1989).

Finer resolution is warranted if species presence and/or interaction strengths vary within the main habitat types. Pelagic lake habitats can be subdivided into epilimnion and hypolimnion food webs (Jonsson et al., 2005). Within benthic habitats, further distinction can be made between the surface layer of the epibenthic habitat and the interstitial habitat (Woodward and Warren, 2007). Submerged macrophytes provide yet another type of habitat, which differs in structural complexity from open water (Kovalenko et al., 2011). Plants and other obstacles provide refuges for prey and may hence decrease the strength of predation (Got- 
ceitas and Colgan, 1989), but the effect may vary between predators-prey pairs. For example, some dragonfly larvae use macrophytes as perching sites to increase their predation rates on zooplankton in the water column.

The influence of seasonal phenology and diurnal cycles on measured trophic link strengths depends on the time scales at which data are collected (Warren, 1989; Woodward and Hildrew, 2002; Winemiller, 2007). Species abundances vary in time: even if per-capita predation rates remain constant, food web structure based on year-round data may appear more complex and interconnected than it is in reality (Woodward et al., 2005; but see Warren, 1989). Potential lack of seasonal overlap is particularly important in, but not restricted to, temporary habitats, where the communities undergo rapid changes during assembly (Urban, 2007). Many holometabolous aquatic insects that constitute an important part of food webs in such habitats complete their development within a few weeks. The adults may remain in the same habitat but assume a different role in the food web through different traits and feeding relationships (e.g., diving beetles: Warren, 1989; Klecka and Boukal, 2012) or become terrestrial in the adult stage (e.g., dragonflies, mosquitoes and chironomids) and disappear from the food web (Woodward and Hildrew, 2002). Phytoplankton assemblages in lakes change predictably in time (Reynolds, 1980), leading to seasonally variable strengths of trophic links between primary producers and grazers. Predators and their prey may also differ in daily activity patterns, which affect encounter rates. Diurnal cycles are particularly common in lakes: zooplankton, macroinvertebrates (Chaoboridae) and fish undertake daily vertical (Lampert, 1989) or horizontal (Burks et al., 2002) migration to minimize predation risk and optimize feeding and growing conditions. Main characteristics of these patterns are thus prime candidates for ST traits in lake food webs; see Williamson (1993) for an example.

The hypothetical example in Fig. 1b describes a food web with two habitats (benthic and pelagic) and strong diurnal patterns in both predators and prey. It illustrates that spatiotemporal overlap can change the overall strength of trophic links, individual-predator PPMR values, and diet breadths. Using only predator ST traits (habitat use and diurnal pattern) would detect stronger predation during the day and increased PPMR in diurnal benthic predators. Added prey ST traits reveal non-overlapping diets in the diurnal predators and identical diets with prey-specific PPMRs in the nocturnal predators.

\section{Predator foraging traits}

Traits characterizing foraging behaviour fall into three broad groups: foraging (search) mode, detection mode and feeding mode (Greene, 1983; Peckarsky, 1984; Klecka and Boukal, 2013). Foraging mode describes the movement and overall activity of the predator and, together with detection mode, determines encounter rates with prey items, while feeding mode describes how the predator subdues and consumes the prey upon encounter (Fig. 1c). Each mode can be classified into several more or less distinct categories. I briefly discuss the classifications and subsequently illustrate the underlying behavioural and morphological traits.

Two major categories of foraging mode can be recognized across taxa: active (searching; stalk and ambush) and passive. Active predators seek prey in contrast to passive predators, which intercept prey while remaining immobile for longer periods of time, although they might occasionally change location. Passive predators employ sit-and-wait and filtration strategies; the former rely on active prey in standing waters, while the latter generate a feeding current (Greene, 1983; Peckarsky, 1984; Montagnes et al., 2008). Prey detection by aquatic predators is predominately tactile and visual; use of olfactory cues as main signals is uncommon and apparently absent in many metazoans (Greene, 1983; Peckarsky, 1984) but common in protists (Montagnes et al., 2008). Concurrent use of mechanical and visual stimuli is, however, common and their relative importance can change during ontogeny (Pritchard, 1965).

Feeding modes include filtering, scraping, engulfing/ swallowing of whole prey, crushing and chewing, tearing, and piercing/external feeding in which the predators feed on the prey by means of extraoral digestion (Peckarsky, 1984; Sibbing and Nagelkerke, 2000). Predators that switch between different feeding tactics should be assigned to different categories proportionally to the time spent using each tactics. This requires direct observations in the field or in carefully designed laboratory experiments and may be further extended to cover context-dependent foraging strategies, e.g. when predators switch from passive to active foraging mode under decreasing prey densities (Formanowicz, 1982; Johansson, 1991), which are beyond the scope of this paper.

For the purpose of model (1), known morphological and behavioural adaptations to find and subdue their prey can be used to classify predators into predefined foraging categories, e.g. as in Wirtz (2012) and Klecka and Boukal (2013), or the traits can be used directly in the trait matrix. The second option can be useful in taxa for which observations of foraging behaviour and stomach content analyses are lacking, and their putative diet must be inferred from morphology alone. It is clear that morphology alone cannot be used as a panacea, given that many related taxa with similar morphology have very different diets, but its prudent use can be invaluable in data-poor situations. For example, gut length and other details of the digestive system can distinguish predators from herbivores (Dumay et al., 2004). Details of the sensory apparatus often belie the hunt- 
ing mode: comparatively larger or more complex eyes indicate visually hunting predators, while specialized mechanical and olfactory receptors (long setae and sensory organs in cuticle in invertebrates; neuromasts of lateral line and mouth barbels in fish) characterize predators that rely on mechanical and chemical stimuli (Pastorok, 1981; Piet, 1998; Rebora et al., 2004).

Sit-and-wait predators and stalkers forage on moving prey; this behaviour is often linked to further behavioural or morphological adaptation enabling a fast strike (e.g., rapid protraction of the modified labium in dragonfly larvae: Pritchard, 1965). Active predators can be further classified by the geometry of movement (Čech and Kubečka, 2002; Jakobsen et al., 2005), which may have significant impact on predation rates. Protists using chemical stimuli can be further divided into chemotactic (directed movement toward stimulus) and chemokinetic (non-directed movement induced by stimulus) predators (Montagnes et al., 2008).

Morphology also affects the ability of predators to successfully capture and handle prey upon encounter (Fig. 1c). Adaptations range from modifications allowing protozoan predators to handle multiple prey simultaneously (Boenigk and Arndt, 2002) to modification of mouthparts into sucking, piercing or engulfing structures in aquatic insects (Peckarsky, 1984) to changes of gill raker number and morphology in zooplanktivorous fish (Amundsen et al., 2004) and larger jaw muscles and changes in jaw-lever mechanics in molluscivorous fish (Wainwright and Richard, 1995; Mittelbach et al., 1999). These adaptations increase predation rates on the focal prey and may simultaneously lead to specialized diets (Fig. 1c).

\section{Prey vulnerability traits}

Vulnerability traits can involve behavioural, morphological and chemical components. Prey vulnerability can be described by two sides of the same coin: as prey attractiveness for predators or as its level of defences (Fig. 1c). The latter are often divided into pre-contact (primary) defences that lower the chance of being discovered by the predators, and hence decrease the encounter rates, and post-contact (secondary) defences that lower the capture probability by avoiding or escaping the predator before, during or after attack (Greene, 1983; Peckarsky, 1984).

Many species are able to detect predation risk and respond to it by adjusting their behaviour as a form of precontact behavioural defence. The most widespread responses to predation risk are reduced overall activity, camouflage behaviour and flexible (micro)habitat choice that can be quantified as the proportion of time spent in refuge or a proportional decrease in activity when presented with predator stimuli (Werner et al., 1983; Werner and Anholt, 1993). Post-contact behavioural responses of metazoans include mainly rapid escape, hiding and immobilization or thanatosis (i.e., feigning death); startle displays and retaliation are less common in standing water taxa (Greene, 1983; Peckarsky, 1984). Protist defensive strategies involve mainly exopolymer capsule formation, prey stickiness and hydrophobicity, all of which are effective at the sub-millimetre scale (Montagnes et al., 2008). Rapid escape relies on high burst swimming speed, saltatory behaviour and elaborate escape trajectories (Domenici and Blake, 1997; Dayton et al., 2005; Jakobsen et al., 2005). Withdrawal into a hiding place may rely on ad-hoc retreat in structurally complex habitats or on the use of pre-existing retreat structures, e.g. burrows in benthic species and larval cases in caddisflies. Immobilization and thanatosis are efficient against predators that rely on movement stimuli (Pritchard, 1965) and may also allow prey to confuse the predator and subsequently escape (Hellsten et al., 1999; Gyssels and Stoks, 2005; Scarton et al., 2009). Behavioural responses may vary between and within taxa; recent research has linked intraspecific variation in prey vulnerability and defensive behaviour to behavioural syndromes (Sih et al., 2004). Boldness may be responsible for differential mortality as bold individual are more likely to take risks during foraging and dispersal and hence have higher mortality (Biro and Post, 2008; Pruitt et al., 2012).

Morphological defences are common in freshwater animals (Dodson, 1988; McCollum and Leimberger, 1997; Relyea, 2001; Mikolajewski and Rolff, 2004). Precontact morphological defences include transparency and visual camouflage; post-contact defences rely on body armour and development of various spines (Dodson, 1988; Jürgens and Matz, 2002; Fig. 1c). Transparency is a common defensive strategy in pelagic zooplankton that can be assessed quantitatively in percents of light transmitted through the body or individual parts (Kerfoot, 1982). Body armour and spines can be characterized by morphometric measurements summarizing their number, extent, length, thickness or crushing resistance (Osenberg and Mittelbach, 1989; Walker, 1997). Simple quantitative traits for camouflage efficiency are more challenging to develop as camouflage involves a number of different strategies and its efficiency depends on context and characteristics of the habitat (Stevens and Merilaita, 2009).

Chemically defended prey are distasteful to the predators. Unpalatability is rarely signalled in animals living in standing freshwater and red water mites might be the only aposematic prey (Kerfoot, 1982; but see Proctor and Garga, 2004). For example, adult beetles of the families Dytiscidae and Gyrinidae excrete defensive substances that deter fish (Peckarsky, 1984), but their colouration is not aposematic to discourage potential predators. For the same reason, Batesian and other types of mimicry do not need to be considered among prey vulnerability traits in freshwater food webs unlike in many terrestrial systems. As with many other foraging and vulnerability traits, un- 
palatability is context-dependent (Gunzburger and Travis, 2005), which makes it a challenging trait to quantify across the whole food web.

\section{Multi-trait food webs: trait interactions and the curse of multidimensionality}

Model (1) can be used to infer underlying processes from data on trophic link strengths or to predict trophic link strength from known relationships between traits and predation. However, given the multitude of traits summarized above, can it ever yield useful insights? Matrix $C$ is symmetric, i.e., model (1) has $1+n+\frac{n}{2}(n+1)$ parameters, where $n$ is the total number of predator and prey traits. One predator and one prey characteristic in each of the three traits groups $(n=6)$ already yields 28 parameters (one for $a_{0}$, six for vector $\mathrm{b}$ and 21 for matrix $C$ ), and their number increases rapidly with additional traits.

Several approaches can help escape this curse of multidimensionality. Simplified models (1) that include only 1-2 of the three trait groups can be investigated and competing models compared using information theory criteria. For larger datasets, techniques such as dimension reduction for regression (Adragni and Cook, 2009) can be used to decrease the number of traits entering model (1), but working examples on trophic link strengths are lacking. Model (1) can also be simplified by assuming no statistical interactions between some of the traits and setting some entries in vector $\mathrm{b}$ and matrix $C$ to zero. Klecka and Boukal (2013) applied this approach to experimental data on 13 aquatic insect predators feeding on 8 types of prey. They considered eight traits: predator and prey body size, one ST trait for both predators and prey (microhabitat use), and four FV traits (prey activity and escape ability, and predator foraging mode and feeding mode). They reduced the full model (1) to a simpler one with 15 parameters by setting all off-diagonal matrix blocks $C_{k l}$ and linear term coefficients $b^{S T}$ and $\tilde{b}^{S T}$ to zero. The best fit of model (1) to the data in the sense of the lowest AICc score kept all predator and prey traits but it contained only 11 nonzero parameters (for details see Klecka and Boukal, 2013).

When will be such simplifications of model (1) justified? Matrix block $C_{I I}$ and linear term coefficients $b_{w}$ and $b_{\tilde{w}}$ describe the contributions of predator and prey body sizes in equation (1). Meta-analyses and experiments suggest that PPMR values in local food webs can remain constant, increase or decrease with predator body size (Barnes et al., 2010; Naisbit et al., 2011; Riede et al., 2011; Klecka and Boukal, 2013). The size allometry of PPMR can also be affected by taxonomic identity (Brose et al., 2006; Bersier and Kehrli, 2008; Naisbit et al., 2011) and predator foraging traits (Wirtz, 2012; Klecka and Boukal, 2013). This means that $C_{l l}$ and/or coefficients $b_{w}$ and $b_{\tilde{w}}$ cannot be assumed zero.

Nonzero elements of matrix block $C_{22}$ and/or linear terms $b_{i}^{S T}$ and $\tilde{b}_{i}^{S T}$ arise when the overall trophic link strengths depend on ST traits (Fig. 1b). Matrix block $C_{33}$ and linear terms $b_{i}^{F V}$ and $\tilde{b}_{i}^{F V}$ describe similar impacts of FV traits (Fig. 1c). Only some ST traits may have such influence, e.g. when the overall strength varies in time but not in space (Fig. 1b). Blocks $C_{12}$ and $C_{13}$ of matrix $C$ describe differential effects of ST and FV traits on predator and prey size allometries. Their elements will be zero when the respective traits only multiply the size-dependent relationship (as in Fig. 1b with data restricted to the pelagic food web and prey classified only by size). This is probably uncommon in real food webs. First, Pawar et al. (2012) showed that trophic interaction strengths scale with predator body mass with respective exponents ranging between -0.32 and -0.15 in $3 \mathrm{D}$ and between 0 and 0.06 in $2 \mathrm{D}$ environments, which implies non-zero elements in block $C_{12}$ for food webs spanning both pelagic and benthic habitat (as in Fig. 1b). Second, block $C_{13}$ should be considered non-zero for taxonomic or trophic groups with known modifications (shifts) of the baseline size allometries by predator or prey traits. Wirtz (2012) described such shifts for predatory marine copepods, in which the three distinguished feeding modes (raptorial carnivory, herbivory and detritivory) differed in the intercept of the common underlying PPMR allometry. Similarly, Klecka and Boukal (2013) found a common slope but different intercepts for PPMR allometries and different strengths of trophic links in predatory aquatic insects with suctorial and chewing feeding mode.

Block $C_{23}$ of the interaction matrix captures how space and time mediate differences in predation rates arising from FV traits. This is particularly relevant for studies aiming at high temporal resolution. For example, light levels can change the probability of successful attack upon encounter: visually hunting predators are less efficient at low light levels (Peckarsky, 1982; Gergs et al., 2010), while predators relying on hydrodynamical signals generated by prey movement (Pastorok, 1981; Peckarsky, 1982) can be equally successful during day and night. In a long-term study of a model zooplankton community, Williamson (1993) elegantly illustrated that the interactions between ST and FV traits may be taxon specific. While the rotifer Polyarthra vulgaris Carlin faced the same predation risk from the predatory copepod Mesocyclops edax (Forbes) and predatory rotifer Asplanchna girodi De Geurne through a balanced trade-off between spatiotemporal overlap with the predators and vulnerability to predation, two other rotifers (Kellicottia bostoniensis (Rousselet) and Keratella crassa Ahlstrom) faced different predation risks from both species of predators that were mediated by asymmetric shifts in spatiotemporal overlap and vulnerability. Two more prey in that study (rotifers Ascomorpha ovalis Carlin and Keratella cochlearis (Gosse)) had nearly identical spatiotemporal 
overlap with Asplanchna and Mesocyclops and their vulnerability to each predator hence did not differ.

Finally, matrix block $C_{33}$ in equation (1) inherently contains non-zero off-diagonal elements: interactions between predator foraging traits and prey vulnerability traits are likely to be ubiquitous and can occur both within and between the sets of predator and prey traits. Figure 1c shows an example in which a generalist predator with unspecialized mouthparts feeds on both undefended and defended prey, while a predator with modified mouthparts specializes on the defended prey. The generalist predator eats less prey, cannot efficiently handle large defended prey, and has therefore higher individual-predator PPMR than the specialist. Predation success will also depend on prey escape abilities and their interaction with predator feeding mode. For example, predatory zooplankton that uses a feeding current can efficiently catch prey whose escape speed is slower than the current (Jakobsen et al., 2005). In the study mentioned above, Williamson (1993) found yet another interaction between prey escape behaviour and predator foraging mode: the jumping escape response of Polyarthra was highly efficient against Asplanchna but not against the rapidly pouncing Mesocyclops. Experiments on prey selectivity in predatory aquatic insects from small fishless pools revealed a similar pattern: searching predators had lower predation rates on prey capable of rapid escape than on slow-escape prey, while predation rates of sit-and-wait predators were similar for both prey groups (Klecka and Boukal, 2013). Interactions of antipredator morphology and antipredator behavioural prey traits also modify trophic link strengths: all else being equal, prey investing more in morphological defences will have slow or no escape reaction (e.g., molluscs) and will change foraging behaviour less than undefended prey under predation risk (Abrahams, 1995).

\section{Multi-trait food webs: size allometries of predation}

In addition to setting some elements of vector $b$ and matrix $C$ to zero, size allometries of predation can be used to standardize other traits with respect to body size (Winemiller, 1991; Pawar et al., 2012) and to consider only the trait residuals in model (1), or to scale the traits away altogether if the residuals are small. Foraging, detection and feeding modes can all affect size allometry of predation. Mechanistic explanations for such size allometries are available or can be developed for many predator groups. Mussels and other passive filter-feeders provide a particularly simple example. Unless the organism applies postcapture prey selection, all attacks are successful and predation rates equal filtering rates. The latter are proportional to the size of the feeding apparatus, which scales with body mass with an exponent of 0.67 if the animal grows isometrically (Sebens, 1982).

Many studies of predation allometries in aquatic habitats have dealt with pre-contact processes in visual predators hunting sedentary or slow-moving prey, for which per-capita prey encounter rates are derived from prey densities and the search rate of the predator, i.e. the volume of water or the area of bottom surface searched per unit time (Persson et al., 1998). The search rate of moving, visually hunting predators is assumed to be equal to the product of swimming speed and the visual field of the predator that may scale allometrically with its size; the scaling exponent approximately equals 0.8 (Andersen and Beyer, 2006). The ability to detect prey items is determined by predator's visual acuity that scales with an exponent of $\sim 0.11$ with its body mass, based on a limited set of experiments in fish (McGill and Mittelbach, 2006). The allometry of predation is affected by both predator and prey traits if the prey also moves. This is always the case for sit-and-wait predators, while per-capita prey encounter rates are a product of prey density, prey speed and predator's reactive volume or distance (Greene, 1983).

Predator traits involved in capturing and subduing prey, such as the gape size, bite force and mouth opening/closing velocity in fishes, also scale allometrically with body size. Suction-feeding predatory fishes, for example, generate external water current that drags the prey into the predator's mouth. Size allometries of suction feeding kinematics may partially explain the observed differences in prey composition among such predators, but the underlying mechanisms are complex and not fully understood (Van Wassenbergh et al., 2005; Wainwright et al., 2007). Measurements in African catfish Glarias gariepinus (Burchell) further suggest that the slope of the relevant intraspecific allometry may change during ontogenetic diet shift (Herrel et al., 2005). Other nuances of predator morphology ranging from relative size and shape of fins determining fine-scale manoeuvrability in fish (Dumay et al., 2004) to jaw mechanics (Wainwright and Richard, 1995; Herrel et al., 2005) to foraging behaviour (e.g., sinusoidal swimming of zooplanktivorous fish: Čech and Kubečka, 2002), may further affect the size allometry in ways not easily amenable to descriptions by simple functional relationships.

Last but not least, size dependencies and allometries of prey vulnerability traits are relatively little understood apart from prey overall activity and prey escape behaviour (Lundvall et al., 1999). The crab Trichodactylus panoplus (von Martens) provides an example of intraspecific size dependence of a post-contact defensive behavioural trait: larger individuals remain in thanatosis for shorter times (Scarton et al., 2009). Known relationships indicate that variation in defence allometries can be high, requiring nonzero prey-related elements in block $C_{13}$ of the interaction matrix. For example, Osenberg and Mittelbach (1989) found that the probability of a snail shell being crushed by 
molluscivorous fish of a given size was tightly correlated with its mechanical crushing resistance and that the slopes of mass-resistance allometries in 11 species of snails were taxon-specific and varied between 0.71 and 3.21.

\section{DISCUSSION}

The required amount of detail in the description of food web structure depends on the purpose of the study. Many empirical (Brose et al., 2006; Gilljam et al., 2011) and theoretical (Williams and Martinez, 2000; Beckerman et al., 2006) studies of food webs focus on connectance and other properties that can be described by binary data: the feeding link between a given pair of species is considered either present or absent. Such datasets may however suffer from sampling effects (Nakazawa et al., 2011; Woodward and Warren, 2007). In addition, binary data do not distinguish between strong and weak trophic links, while many empirical studies report prevalence of weak interactions over strong ones in natural food webs and experiments and theoretical models indicate that this pattern may be crucial for food web persistence and stability (Yodzis, 1981; De Ruiter et al., 1996; Rooney and McCann, 2012). This emphasizes the importance of alternative approaches to identify key mechanisms and scaling relationships that underlie food web structure (Berlow et al., 2004) and the necessity to consider quantitative descriptors of food webs (Bersier et al., 2002).

\section{Multi-trait approaches and functional groups in aquatic food webs}

As I have documented in this paper, body size does not explain all observed variation in trophic links in standing waters. Even for binary data, the inclusion of a few traits, such as the habitat use of the consumer or mobility of the resource, can substantially increase the proportion of correctly predicted food webs links (Eklöf et al., 2013). Trait-based approaches can thus complement expert knowledge and relatively sparse matrices of observational data in describing the structure of aquatic food webs; although I have focused on standing waters, the structure of model (1) can also be applied to marine food webs and running waters. Trait-based descriptions can draw from the concept of trophic species that lump together taxa with similar diets (Dunne et al., 2002; Woodward, 2009). Individual taxa within a trophic species can be assumed functionally redundant if their other important functional traits, such as energy transfer or bioturbation rates, are also similar (Covich et al., 1999; Chalcraft and Resetarits, 2003; Petchey and Gaston, 2006). Quantitative estimates of trophic links can thus be based on the degree of trait similarity to other predator-prey pairs in which the strengths have been measured. This approach can reduce the complexity of real food webs to tractable levels, but the diets of a sufficient proportion of predators must be known in the first place.

Evidence of the presence of a trophic link, let alone its magnitude, is lacking for many putative predator-prey pairs in food webs in standing waters. The picture is especially dire for aquatic arthropods, which constitute the largest proportion of metazoan biodiversity in standing waters. For example, Brandl (2005) reported that data about feeding on rotifers exist for only 30 out of 600 species of cyclopoid copepods, all of which are likely to have rotifers in their diet. Some data on prey selectivity exist for less than 40 species of predatory aquatic beetles, nepomorphan bugs and dragonfly larvae (Klecka and Boukal, 2012), although their global diversity in standing waters exceeds several thousand species and dozens or hundreds of them can occur at a single site (Klečka and Boukal, 2011). It remains an open question how many predator-prey links in a food web need to be measured before we can reliably predict the strength of all remaining links.

We currently lack an integrative approach that would jointly consider all taxonomic groups, trophic levels and traits other than body size to describe the structure of aquatic food webs. As the three groups of traits used in model (1) - body size, measures of spatiotemporal overlap, and predator foraging and prey vulnerability traits resonate through the literature, model (1) with components specified by eqs. (3-5) can be used to establish quantitative links between measurable traits and trophic link strengths under a common formula. It also provides a conceptual framework to investigate effects of non-additive effects of predator and prey traits on trophic interactions. Traits found relevant for the description of feeding links may also provide basis for broader characterisations of functional groups (Steneck and Watling, 1982; Reynolds et al., 2002) instead of a combination of taxonomy and size-based classification.

Although I have focused on predation, the proposed approach can also cover aquatic herbivores and detritivores and their resources with only minor modifications. Prey mortality in model (1) should be replaced by mass consumption rate to include feeding on macrophytes and plant detritus, and prey vulnerability traits can be supplemented by or replaced with characteristics of resource quality (Beckerman, 2005). Other traits including prey size can remain in place.

\section{Integrating size-based views with other traits: role for metabolic ecology, animal personalities and ecomorphology}

Finding a unique partition of the variation in data on trophic link strengths between traits (in the sense of finding a set of phenotypic traits and parameters in equation (1) that best describe the data) may be difficult as body 
size correlates with other life history, morphological, behavioural and trophic traits. To unravel the true dimensionality of the trophic niche space, observable phenotypic traits may need to be transformed to uncorrelated abstract trophic traits (Rossberg et al., 2009). While this issue is of limited interest in studies that work with few traits, limited numbers of predator-prey pairs and/or focus on a few defined questions (Wirtz, 2012; Klecka and Boukal, 2013), it will be relevant for large datasets. Multivariate statistical analyses could be used to extract uncorrelated abstract trophic traits from the data (Rossberg et al., 2009), but such abstract traits might be difficult to interpret. Another approach could utilize recent advances in metabolic ecology (Sibly et al., 2012) and scaling of behaviour (Dial et al., 2008) and use theoretically proposed size allometries (Pawar et al., 2012) to scale away the effects of body size and focus on residual variation in the remaining traits. Hence, a fruitful area for research is to establish allometries for various traits within and across taxonomic groups and habitats. This approach does not guarantee that the residual ST and FV traits become uncorrelated; we currently lack theoretical predictions of how these other traits could covary.

Recent advances in the research on animal personalities, behavioural syndromes and slow-fast life history continua provide starting points to investigate the relationship between trophic links and behavioural traits (Johansson, 2000; Sih et al., 2004; Dial et al., 2008). Ecomorphology, which relates morphological adaptations in individuals to their ecological role, is a natural platform to study morphological traits. It can yield detailed insight into predation, especially when multiple traits are considered to minimize the risk of discovery of non-causal correlations between a given trait and predation rate (Koehl, 1996). The paradigm that morphology constrains the potential and realized niche, including habitat use and diet composition, has been central to ecomorphological studies of fishes (Webb, 1984; Wainwright, 1991; Sibbing and Nagelkerke, 2000). In other aquatic groups this approach has been followed rarely (Giacomini and De Marco, 2008; Rotheray, 2013) and has not lead to direct, quantitative links between morphological traits and diet. For example, Giacomini and De Marco (2008) found differences in body shape between similarly sized dragonfly larvae from the family Libellulidae that occupy either bottom substrate or aquatic macrophytes, but their study fell short of linking larval morphology to diet.

\section{Integrating size-based views with other traits: prey defences and the lock-and-key mechanism}

Describing the interactions between prey vulnerability and predator foraging traits is, in my opinion, one of the main challenges in developing a unified framework for interaction strengths in freshwater food webs. This challenge is reflected in the asymmetry of top-down $v s$. bottom-up views on trophic link strengths: diet similarity is commonly used to define trophic species, but the complementary question of predator-based grouping of prey is rarely pursued (but see Klecka and Boukal, 2012). Defence trait can be relatively easily quantified within one taxon, but generalizations across entire food webs spanning protozoans, invertebrates and fish will be difficult. Relative prey vulnerability to different types of predators depends on the traits chosen to distinguish the predators (Chalcraft and Resetarits, 2003). Given the many differently sized predators using a diversity of predation strategies in freshwater food webs, all morphological and behavioural defences are ultimately predator-specific and may increase vulnerability to other types of predators (Sih et al., 1998). For example, shells defend snails well against general predators that lack morphological or behavioural adaptations to break into the shell (Klecka and Boukal, 2013) but prevent them from escaping molluscivorous fish (Mittelbach et al., 1999).

\section{Integrating size-based views with other traits: variation in predation rates}

Last but not least, context-dependent predation rates can render statistical analyses such as those summarized in model (1) problematic (Koehl, 1996). Strengths of trophic interactions may vary in time and space due to nonlinear functional responses, optimal foraging behaviour and predator interference (Berlow et al., 2004) at timescales driven by other abiotic conditions (e.g., seasonality: Woodward et al., 2005), phenotypic plasticity of predators and prey (Miner et al., 2005) and potential evolutionary changes (Nakazawa et al., 2007). Known examples of seasonal dynamics of trophic link strengths in freshwater food webs are few and apart (Jonsson et al., 2005; Warren, 1989; Woodward and Hildrew, 2002). Their generalization across habitats is currently impossible: the underlying mechanisms are patchily understood. Temperature strongly affects predation rates (Rall et al., 2012; Dell et al., 2013) and could be the main driver after accounting for changes in body size, ST and FV traits. However, individual ontogeny and species phenology also play significant roles in the variation of trophic interactions (Rudolf and Rasmussen, 2013). Organisms have higher metabolic requirements during periods of growth, and fast-growing organisms may thus have much larger mass-specific prey consumption rates as larvae than as adults (e.g., diving beetles: Klecka and Boukal, 2012). Other predators that require energy reserves to reproduce may exert higher predation pressure before or during reproduction.

Another challenge is to quantify the effect of diurnal behavioural patterns and foraging (Dieguez and Gilbert, 2003; Gergs et al., 2010) on food webs. If food web in- 
teractions differ between day and night, are the differences equal across all types of standing freshwater habitats? Are the same or different taxa and functional groups involved? Which species do, like Dr Jekyll and Mr Hyde, move around as prey during the day and become predators during the night? Detailed answers to these questions would not only advance our understanding of dynamical changes in food web structure, but would also help rebuild community ecology from environmentally specific functional traits (McGill et al., 2006).

\section{CONCLUSIONS AND PERSPECTIVES}

Body size has become the common and pervasive currency in studies of trophic interactions in aquatic food webs and functioning of aquatic ecosystems (Hildrew et al., 2007). The enormous success of size-based approaches has overshadowed the role of other traits in predator-prey interactions. Given the great potential but also the limitations of purely size-based approach, the scope of research on trophic interactions should be widened to encompass traits characterizing key aspects of predator and prey life history, morphology and behaviour. There is also ample evidence that the roles of body size and other traits in predation may vary across environments as well as spatial and temporal scales.

Current paucity of well resolved quantitative data on food webs in standing waters calls for further field and laboratory studies on predation rates and prey selectivity across taxa and habitats. Analyses of the data can identify candidate traits for the feeding niche, and departures of these traits from body size allometries can be used to reveal additional dimensions of the niche. Data on many promising traits are already accessible in the literature and additional traits are beginning to emerge in studies on animal personalities, metabolic ecology and ecomorphology. Multi-trait food web models can test whether these additional traits affects the structure, stability and other properties of food webs. These complementary approaches can help resolve the roles of taxonomic identity, body size and other traits in the structuring of food webs in standing waters and other aquatic habitats.

\section{ACKNOWLEDGMENTS}

I thank D. Fontaneto for the invitation to contribute to this special issue, K. Šimek for help on relevant papers on protozoans, J. Klečka and A. Rossberg for discussions on multi-trait descriptions of food webs, and O. Petchey, A. Sentis and two anonymous reviewers for comments and criticisms that helped improve the paper. This work was supported by the EU Marie Curie European Reintegration Grant 'AquaMod' (PERG04-GA-2008-239543) and Grant Agency of the Czech Republic (GACR P505/10/0096).

\section{REFERENCES}

Abrahams MV, 1995. The interaction between antipredator behaviour and antipredator morphology: experiments with fathead minnows and brook sticklebacks. Can. J. Zool. 73:2209-2215

Adragni KP, Cook RD, 2009. Sufficient dimension reduction and prediction in regression. Philos. T. R. Soc. A 367:4385-4405.

Allesina S, Alonso D, Pascual M (2008) A general model for food web structure. Science 320:658-661.

Amundsen P-A, Bøhn T, Våga GH, 2004. Gill raker morphology and feeding ecology of two sympatric morphs of European whitefish (Coregonus lavaretus). Ann. Zool. Fenn. 41:291-300.

Andersen KH, Beyer JE, 2006. Asymptotic size determines species abundance in the marine size spectrum. Am. Nat. 168:54-61.

Barnes C, Maxwell D, Reuman DC, Jennings S, 2010. Global patterns in predator-prey size relationships reveal size dependency of trophic transfer efficiency. Ecology 91:222-232.

Basset A, Barbone E, Borja A, Brucet S, Pinna M, Quintana XD, Reizopoulou S, Rosati I, Simboura N, 2012. A benthic macroinvertebrate size spectra index for implementing the Water Framework Directive in coastal lagoons in Mediterranean and Black Sea ecoregions. Ecol. Indic. 12:72-83.

Beckerman AP, 2005. The shape of things eaten: the functional response of herbivores foraging adaptively. Oikos 110:591-601.

Beckerman AP, Petchey OL, Warren PH, 2006. Foraging biology predicts food web complexity. P. Natl. Acad. Sci. USA 103:13745-13749.

Berlow EL, Neutel AM, Cohen JE, De Ruiter PC, Ebenman B, Emmerson M, Fox JW, Jansen VAA, Jones JI, Kokkoris GD, Logofet DO, McKane AJ, Montoya JM, Petchey O, 2004. Interaction strengths in food webs: issues and opportunities. J. Anim. Ecol. 73:585-598.

Bersier LF, Kehrli P, 2008. The signature of phylogenetic constraints on food-web structure. Ecol. Complex. 5:132-139.

Bersier LF, Banašek-Richter C, Cattin MF, 2002. Quantitative descriptors of food web matrices. Ecology 83:2394-2407.

Biro PA, Post JR, 2008. Rapid depletion of genotypes with fast growth and bold personality traits from harvested fish populations. P. Natl. Acad. Sci. USA 105:2919-22.

Boenigk J, Arndt H, 2002. Bacterivory by heterotrophic flagellates: community structure and feeding strategies. A. van Leeuw. J. Microb. 81:465-480.

Brandl Z, 2005. Freshwater copepods and rotifers: predators and their prey. Hydrobiologia 546:475-489.

Brose U, 2010. Body-mass constraints on foraging behaviour determine population and food-web dynamics. Funct. Ecol. 24:28-34.

Brose U, Dunne JA, Montoya JM, Petchey OL, Schneider FD, Jacob U, 2012. Climate change in size-structured ecosystems. Philos. T. Roy. Soc. B 367:2903-2912.

Brose U, Jonsson T, Berlow EL, Warren PH, Banasek-Richter C, Bersier LF, Blanchard JL, Brey T, Carpenter SR, Blandenier MFC, Cushing L, Dawah HA, Dell T, Edwards F, Harper-Smith S, Jacob U, Ledger ME, Martinez ND, Memmott J, Mintenbeck K, Pinnegar JK, Rall BC, Rayner TS, Reuman DC, Ruess L, Ulrich W, Williams RJ, Woodward G, Cohen JE, 2006. Consumer-resource body-size relationships in natural food webs. Ecology 87:2411-2417. 
Brown JH, Gillooly JF, Allen AP, Savage VM, West GB, 2004. Toward a metabolic theory of ecology. Ecology 85:1771-1789.

Brucet S, Boix D, Lopez-Flores R, Badosa A, Moreno-Amich $\mathrm{R}$, Quintana XD, 2005. Zooplankton structure and dynamics in permanent and temporary Mediterranean salt marshes: taxon-based and size-based approaches. Arch. Hydrobiol. 162:535-555.

Burks R, Lodge D, Jeppesen E, Lauridsen TL, 2002. Diel horizontal migration of zooplankton: costs and benefits of inhabiting the littoral. Freshwater Biol. 47:343-365.

Čech M, Kubečka J, 2002. Sinusoidal cycling swimming pattern of reservoir fishes. J. Fish Biol. 61:456-471.

Chalcraft DR, Resetarits WJ, 2003. Mapping functional similarity of predators on the basis of trait similarities. Am. Nat. 162:390-402.

Cohen JE, Pimm SL, Yodzis P, Saldaña J, 1993. Body sizes of animal predators and animal prey in food webs. J. Anim. Ecol. 62:67-78.

Covich AP, Palmer MA, Crowl TA, 1999. The role of benthic invertebrate species in freshwater ecosystems: zoobenthic species influence energy flows and nutrient cycling. BioScience 49:119-127.

Dayton GH, Saenz D, Baum KA, Langerhans RB, DeWitt TJ, 2005. Body shape, burst speed and escape behavior of larval anurans. Oikos 111:582-591.

Dell AI, Pawar S, Savage VM, 2013. Temperature dependence of trophic interactions are driven by asymmetry of species responses and foraging strategy. J. Anim. Ecol 83:70-84.

Dial KP, Greene E, Irschick DJ, 2008. Allometry of behavior. Trends Ecol. Evol. 23:394-401.

Dieguez MC, Gilbert JJ, 2003. Predation by Buenoa macrotibialis (Insecta, Hemiptera) on zooplankton: effect of light on selection and consumption of prey. J. Plankton Res. 25:759-769.

Dodson SI, 1988. Cyclomorphosis in Daphnia galeata mendotae Birge and $D$. retrocurva Forbes as a predator-induced response. Freshwater Biol. 19:109-114.

Domenici P, Blake RW, 1997. The kinematics and performance of fish fast-start swimming. J. Exp. Biol. 1178:1165-1178.

Dossena M, Yvon-Durocher G, Grey J, Montoya JM, Perkins DM, Trimmer M, Woodward G, 2012. Warming alters community size structure and ecosystem functioning. P. Roy. Soc. B-Biol. Sci. 279:3011-3019.

Drossel B, Higgs PG, McKane AJ, 2001. The influence of predator-prey population dynamics on the long-term evolution of food web structure. J. Theor. Biol. 208:91-107.

Dumay O, Tari P, Tomasini J, Mouillot D, 2004. Functional groups of lagoon fish species in Languedoc Roussillon, southern France. J. Fish Biol. 64:970-983.

Dunne JA, Williams RJ, Martinez ND, 2002. Network structure and biodiversity loss in food webs: robustness increases with connectance. Ecol. Lett. 5:558-567.

Edgar JE, 1990. The use of the size structure of benthic macrofaunal communities to estimate faunal biomass and secondary production. J. Exp. Mar. Biol. Ecol. 137:195-214.

Eklöf A, Jacob U, Kopp J, Bosch J, Castro-Urgal R, Chacoff NP, Dalsgaard B, de Sassi C, Galetti M, Guimarães PR, Lomáscolo SB, González AMM, Pizo MA, Rader R, Rodrigo A, Tylianakis JM, Vázquez DP, Alessina S, 2013. The dimensionality of ecological networks. Ecol. Lett. 16:577-583.
Emmrich M, Brucet S, Ritterbusch D, Mehner T, 2011. Size spectra of lake fish assemblages: responses along gradients of general environmental factors and intensity of lake-use. Freshwater Biol. 56:2316-2333.

Formanowicz DR, 1982. Foraging tactics of larvae of Dytiscus verticalis (Coleoptera: Dytiscidae): the assessment of prey density. J. Anim. Ecol. 51:757-767.

Frank KT, Petrie B, Choi JS, Leggett WC, 2005. Trophic cascades in a formerly cod-dominated ecosystem. Science 308:1621-1623.

Garcia SM, Kolding J, Rice J, Rochet M-J, Zhou S, Arimoto T, Beyer JE, Borges L, Bundy A, Dunn D, Fulton EA, Hall M, Heino M, Law R, Makino M, Rijnsdorp AD, Simard F, Smith ADM, 2012. Reconsidering the consequences of selective fisheries. Science 335:1045-1047.

Gergs A, Hoeltzenbein N, Ratte H, 2010. Diurnal and nocturnal functional response of juvenile Notonecta maculata considered as a consequence of shifting predation behaviour. Behav. Process. 85:151-156.

Giacomini HC, De Marco P, 2008. Larval ecomorphology of 13 Libellulidae (Anisoptera, Odonata) of the Middle Rio Doce Valley, Minas Gerais, Brazil. Braz. J. Biol. 68:211-219.

Gilljam D, Thierry A, Edwards FK, Figueroa D, Ibbotson ATJ, Jones JI, Lauridsen RB, Petchey OL, Woodward G, Ebenman B, 2011. Seeing double: size-based versus taxonomic views of food web structure. Adv. Ecol. Res. 45:67-133.

Gotceitas V, Colgan P, 1989. Predator foraging success and habitat complexity: quantitative test of the threshold hypothesis. Oecologia 80:158-166.

Greene CH, 1983. Selective predation in freshwater zooplankton communities. Int. Rev. ges. Hydrobio. 68:297-315.

Gunzburger MS, Travis J, 2005. Critical literature review of the evidence for unpalatability of amphibian eggs and larvae. J. Herpetol. 39:547-571.

Gyssels FGM, Stoks R, 2005. Threat-sensitive responses to predator attacks in a damselfly. Ethology 111:411-423.

Harper-Smith S, Berlow EL, Knapp RA, Williams RJ, Martinez ND, 2005. Communicating ecology through food webs: visualizing and quantifying the effects of stocking alpine lakes with trout, p. 407-423. In: P.C. de Ruiter, V. Wolters, and J.C. Moore (eds.), Dynamic food webs: multispecies assemblages, ecosystem development and environmental change. Academic Press.

Havens K, 1992. Scale and structure in natural food webs. Science 257:1107-1109.

Hellsten M, Lagergren R, Stenson J, 1999. Can extreme morphology in Bosmina reduce predation risk from Leptodora? An experimental test. Oecologia 118:23-28.

Henri DC, Seager D, Weller T, Van Veen FJF, 2012. Potential for climate effects on the size-structure of host-parasitoid indirect interaction networks. Philos. T. R. Soc. B 367:3018-3024.

Herrel A, Van Wassenbergh S, Wouters S, Adriaens D, Aerts P, 2005. A functional morphological approach to the scaling of the feeding system in the African catfish, Clarias gariepinus. J. Exp. Biol. 208:2091-2102.

Hildrew AG, Raffaelli D, Edmonds-Brown R, 2007. Body size: the structure and function of aquatic ecosystems. Cambridge University Press: 343 pp.

Ings TC, Montoya JM, Bascompte J, Blüthgen N, Brown L, Dormann CF, Edwards F, Figueroa D, Jacob U, Jones JI, 
Lauridsen RB, Ledger ME, Lewis HM, Olesen JM, van Veen FJ, Warren PH, Woodward G, 2009. Ecological networks-beyond food webs. J. Anim. Ecol. 78:253-269.

Jacob U, Thierry A, Brose U, Arntz WE, Berg S, Brey T, Fetzer I, Jonsson T, Mittenbeck K, Möllmann C, Petchey OL, Riede JO, Dunne JA, 2011. The role of body size in complex food webs: a cold case. Adv. Ecol. Res. 45:181-223.

Jakobsen HH, Halvorsen E, Hansen BW, Visser AW, 2005. Effects of prey motility and concentration on feeding in Acartia tonsa and Temora longicornis: the importance of feeding modes. J. Plankton Res. 27:775-785.

Johansson F, 1991. Foraging modes in an assemblage of odonate larvae - effects of prey and interference. Hydrobiologia 209:79-87.

Johansson F, 2000. The slow-fast life style characteristics in a suite of six species of odonate larvae. Freshwater Biol. 43:149-159.

Jonsson T, Cohen JE, Carpenter SR, 2005. Food webs, body size, and species abundance in ecological community description. Adv. Ecol. Res. 36:2-84.

Jürgens K, Matz C, 2002. Predation as a shaping force for the phenotypic and genotypic composition of planktonic bacteria. A. van Leeuw. J. Microb. 81:413-434.

Kerfoot WC, 1982. A question of taste: crypsis and warning coloration in freshwater zooplankton communities. Ecology 63:538-554.

Klečka J, Boukal DS, 2011. Lazy ecologist's guide to water beetle diversity: which sampling methods are the best? Ecol. Indic. 11:500-508.

Klecka J, Boukal DS, 2012. Who eats whom in a pool? A comparative study of prey selectivity by predatory aquatic insects. PloS ONE 7:e37741.

Klecka J, Boukal DS, 2013. Foraging and vulnerability traits modify predator-prey body mass allometry: freshwater macroinvertebrates as a case study. J. Anim. Ecol. 82:1031-1041.

Kleiber M, 1932. Body size and metabolism. Hilgardia 6: 315-353.

Koehl MAR, 1996. When does morphology matter? Annu. Rev. Ecol. Syst. 27:501-542.

Kovalenko KE, Thomaz SM, Warfe DM, 2011. Habitat complexity: approaches and future directions. Hydrobiologia 685:1-17.

Lampert W, 1989. The adaptive significance of diel vertical migration of zooplankton. Funct. Ecol. 3:21-27.

Langenheder S, Jürgens K, 2001. Regulation of bacterial biomass and community structure by metazoan and protozoan predation. Limnol. Oceanogr. 46:121-134.

Litchman E, Klausmeier CA, Schofield OM, Falkowski PG, 2007. The role of functional traits and trade-offs in structuring phytoplankton communities: scaling from cellular to ecosystem level. Ecol. Lett. 10:1170-1181.

Loeuille N, Loreau M, 2005. Evolutionary emergence of sizestructured food webs. P. Natl. Acad. Sci. USA 102:5761-5766.

Lundvall D, Svanbäck R, Persson L, Byström P, 1999. Size-dependent predation in piscivores: interactions between predator foraging and prey avoidance abilities. Can. J. Fish. Aquat. Sci. 56:1285-1292.

Lurgi M, López BC, Montoya JM, 2012. Climate change impacts on body size and food web structure on mountain ecosystems. Philos. T. R. Soc. B 367:3050-3057.
McCollum SA, Leimberger JD, 1997. Predator-induced morphological changes in an amphibian: predation by dragonflies affects tadpole shape and color. Oecologia 109:615-621.

McGill BJ, Enquist BJ, Weiher E, Westoby M, 2006. Rebuilding community ecology from functional traits. Trends Ecol. Evol. 21:178-185

McGill BJ, Mittelbach GG, 2006. An allometric vision and motion model to predict prey encounter rates. Evol. Ecol. Res. 8:691-701.

Messier J, McGill BJ, Lechowicz MJ, 2010. How do traits vary across ecological scales? A case for trait-based ecology. Ecol. Lett. 13:838-48.

Mikolajewski DJ, Rolff J, 2004. Benefits of morphological defence demonstrated by direct manipulation in larval dragonflies. Evol. Ecol. Res. 6:619-626.

Miller TEX, Rudolf VHW, 2011. Thinking inside the box: community-level consequences of stage-structured populations. Trends Ecol. Evol. 26:457-466.

Miner BG, Sultan SE, Morgan SG, Padilla DK, Relyea RA, 2005. Ecological consequences of phenotypic plasticity. Trends Ecol. Evol. 20:685-692.

Mittelbach GG, Osenberg CW, Wainwright PC, 1999. Variation in feeding morphology between pumpkinseed populations: phenotypic plasticity or evolution? Evol. Ecol. Res. 1:111-128.

Montagnes DJS, Barbosa AB, Boenigk J, Davidson K, Jürgens K, Macek M, Parry JD, Roberts E, Šimek K, 2008. Selective feeding behaviour of key free-living protists: avenues for continued study. Aquat. Microb. Ecol. 53:83-98.

Müller UK, Stamhuis EJ, Videler JJ, 2000. Hydrodynamics of unsteady fish swimming and the effects of body size: comparing the flow fields of fish larvae and adults. J. Exp. Biol. 203:193-206.

Naisbit RE, Kehrli P, Rohr RP, Bersier L-F, 2011. Phylogenetic signal in predator-prey body-size relationships. Ecology 92:2183-9.

Nakazawa T, Ishida N, Kato M, Yamamura N, 2007. Larger body size with higher predation rate. Ecol. Freshw. Fish 16:362-372.

Nakazawa T, Ushio M, Kondoh M, 2011. Scale-dependence of predator-prey mass ratio: determinants and applications. Adv. Ecol. Res. 45:269-302.

Neutel AM, Heesterbeek JAP, 2002. Stability in real food webs: weak links in long loops. Science 296:1120-1124.

Osenberg CW, Mittelbach GC, 1989. Effects of body size on the predator-prey interaction between pumpkinseed sunfish and gastropods. Ecol. Monogr. 59:405-432.

Pastorok R, 1981. Prey vulnerability and size selection by Chaoborus larvae. Ecology 62:1311-1324.

Pawar S, Dell AI, Savage VM, 2012. Dimensionality of consumer search space drives trophic interaction strengths. Nature 486:485-489.

Peckarsky BL, 1982. Aquatic insect predator-prey relations. BioScience 32:261-266.

Peckarsky BL, 1984. Predator-prey interactions among aquatic insects, p. 196-254. In: V.H. Resh and D.M. Rosenberg (eds.) The ecology of aquatic insects. Praeger Scientific, New York.

Persson L, Leonardsson K, De Roos AM, Gyllenberg M, Christensen B, 1998. Ontogenetic scaling of foraging rates and 
the dynamics of a size-structured consumer-resource model. Theor. Popul. Biol. 293:270-293.

Petchey OL, Dunne JA, 2012. Predator-prey relations and food webs, p. 86-98. In: R. Sibly, J. Brown and A. Kodric-Brown (eds.), Metabolic ecology: a scaling approach. Wiley-Blackwell, Oxford.

Petchey OL, Beckerman AP, Riede JO, Warren PH, 2008. Size, foraging, and food web structure. P. Natl. Acad. Sci. USA 105:4191-4196.

Petchey OL, Gaston KJ, 2006. Functional diversity: back to basics and looking forward. Ecol. Lett. 9:741-58.

Peters RH, 1983. The ecological implications of body size. Cambridge University Press, Cambridge, UK: 329 pp.

Piet GJ, 1998. Ecomorphology of a size-structured tropical freshwater fish community. Environ. Biol. Fish. 51:67-86.

Poff NL, Olden JD, Vieira NKM, Finn DS, Simmons MP, Kondratieff BC, 2006. Functional trait niches of North American lotic insects: traits-based ecological applications in light of phylogenetic relationships. J. N. Am. Benthol. Soc. 25:730-755.

Pritchard G, 1965. Prey capture by dragonfly larvae (Odonata; Anisoptera). Can. J. Zool. 43:271-289.

Proctor HC, Garga N, 2004. Red, distasteful water mites: did fish make them that way? Exp. Appl. Acarol. 34:127-147.

Pruitt JN, Stachowicz JJ, Sih A, 2012. Behavioral types of predator and prey jointly determine prey survival: potential implications for the maintenance of within-species behavioral variation. Am. Nat. 179:217-27.

Purves D, Scharlemann J, Harfoot M, Newbold T, Tittensor DP, Hutton J, Emmott S, 2013. Time to model all life on Earth. Nature 493:295-297.

Rall BC, Brose U, Hartvig M, Kalinkat G, Schwarzmüller F, Vucic-Pestic O, Petchey OL, 2012. Universal temperature and body-mass scaling of feeding rates. Philos. T. Roy. Soc. B 367:2923-34.

Rall BC, Kalinkat G, Ott D, Vucic-Pestic O, Brose U, 2011. Taxonomic versus allometric constraints on non-linear interaction strengths. Oikos 120:483-492.

Rall BC, Riede JO, Banasek-Richter C, Navarrete SA, Wieters EA, Emmerson MC, Jacob U, Brose U, 2010. Scaling of food-web properties with diversity and complexity across ecosystems. Adv. Ecol. Res. 42:139-170.

Rebora M, Piersanti S, Gaino E, 2004. Visual and mechanical cues used for prey detection by the larva of Libellula depressa (Odonata Libellulidae). Ethol. Ecol. Evol. 16:133-144.

Relyea RA, 2001. Morphological and behavioral plasticity of larval anurans in response to different predators. Ecology 82:523-540.

Reynolds CS, 1980. Phytoplankton assemblages and their periodicity in stratifying lake systems. Holarctic Ecol. 3:141-159.

Reynolds CS, Huszar V, Kruk C, Naselli-Flores L, Melo S, 2002. Towards a functional classification of the freshwater phytoplankton. J. Plankton Res. 24:417-728.

Riede JO, Brose U, Ebenman B, Jacob U, Thompson R, Townsend CR, Jonsson T, 2011. Stepping in Elton's footprints: a general scaling model for body masses and trophic levels across ecosystems. Ecol. Lett. 14:169-178.

Rohr R, Scherer H, Kehrli P, 2010. Modeling food webs: exploring unexplained structure using latent traits. Am. Nat. 176:170-177.
Rooney N, McCann KS, 2012. Integrating food web diversity, structure and stability. Trends Ecol. Evol. 27:40-46.

De Roos AM, Persson L, McCauley E, 2003. The influence of size-dependent life-history traits on the structure and dynamics of populations and communities. Ecol. Lett. 6:473-487.

Rossberg AG, Brännström Å, Dieckmann U, 2009. How trophic interaction strength depends on traits. Theor. Ecol. 3:13-24.

Rotheray EL, 2013. Differences in ecomorphology and microhabitat use of four saproxylic larvae (Diptera, Syrphidae) in Scots pine stump rot holes. Ecol. Entomol. 38:219-229.

Rudolf VHW, Armstrong J, 2008. Emergent impacts of cannibalism and size refuges in prey on intraguild predation systems. Oecologia 157:675-686.

Rudolf VHW, Rasmussen NL, 2013. Ontogenetic functional diversity: size structure of a keystone predator drives functioning of a complex ecosystem. Ecology 94:1046-1056.

De Ruiter PC, Neutel AM, Moore JC, 1996. Energetics and stability in belowground food webs, p. 201-210. In: G.A. Polis and K.O. Winemiller (eds.), Food webs: integration of patterns and dynamics. Chapman \& Hall, New York.

Saiz E, Kiørboe T, 1995. Predatory and suspension feeding of the copepod Acartia tonsa in turbulent environments. Mar. Ecol.-Progr. Ser. 122:147-158.

Scarton LP, Zimmermann BL, Machado S, Aued AW, Manfio D, Santos S, 2009. Thanatosis in the freshwater crab Trichodactylus panoplus (Decapoda: Brachyura: Trichodactylidae). Nauplius 17:97-100.

Sebens KP, 1982. The limits to indeterminate growth: an optimal size model applied to passive suspension feeders. Ecology 63:209-222.

Sibbing FA, Nagelkerke LAJ, 2000. Resource partitioning by Lake Tana barbs predicted from fish morphometrics and prey characteristics. Rev. Fish Biol. Fisher. 10:393-437.

Sibly RM, Brown JH, Kodric-Brown A, 2012. Metabolic ecology: a scaling approach. Oxford, UK: Wiley-Blackwell.

Sih A, Bell A, Johnson J, 2004. Behavioral syndromes: an ecological and evolutionary overview. Trends Ecol. Evol. 19:372-378.

Sih A, Englund G, Wooster D, 1998. Emergent impacts of multiple predators on prey. Trends Ecol. Evol. 13:350-355.

Simek K, Chrzanowski TH, 1992. Direct and indirect evidence of size-selective grazing on pelagic bacteria by freshwater nanoflagellates. Appl. Environ. Microb. 58:3715-3720.

Solimini AG, Della Bella V, Bazzanti M, 2005. Macroinvertebrate size spectra of Mediterranean ponds with differing hydroperiod length. Aquat. Conserv. 15:601-611.

Steneck RS, Watling L, 1982. Feeding capabilities and limitation of herbivorous molluscs: a functional group approach. Mar. Biol. 68:299-319.

Stevens M, Merilaita S, 2009. Animal camouflage: current issues and new perspectives. Philos. T. R. Soc. B 364:423-427.

Suding KN, Lavorel S, Chapin FS, Cornelissen JHC, Díaz S, Garnier E, Goldberg D, Hooper DU, Jackson ST, Navas ML, 2008. Scaling environmental change through the community-level: a trait-based response-and-effect framework for plants. Glob. Change Biol. 14:1125-1140.

Urban MC, 2007. Predator size and phenology shape prey survival in temporary ponds. Oecologia 154:571-80.

Wahlström E, Persson L, Diehl S, Byström P, 2000. Size-depen- 
dent foraging efficiency, cannibalism and zooplankton community structure. Oecologia 123:138-148.

Wainwright PC, 1991. Ecomorphology: experimental functional anatomy for ecological problems. Am. Zool. 31:680-693.

Wainwright PC, Carroll AM, Collar DC, Day SW, Higham TE, Holzman RA, 2007. Suction feeding mechanics, performance, and diversity in fishes. Integr. Comp. Biol. 47:96-106.

Wainwright PC, Richard BA, 1995. Predicting patterns of prey use from morphology of fishes. Environ. Biol. Fish. 44:97-113.

Walker JA, 1997. Ecological morphology of lacustrine threespine stickleback Gasterosteus aculeatus L. (Gasterosteidae) body shape. Biol. J. Linn. Soc. 61:3-50.

Warren PH, 1989. Spatial and temporal variation in the structure of a freshwater food web. Oikos 55:299-311.

Van Wassenbergh S, Aerts P, Herrel A, 2005. Scaling of suctionfeeding kinematics and dynamics in the African catfish, Clarias gariepinus. J. Exp. Biol. 208:2103-2114.

Webb PW, 1984. Body form, locomotion and foraging in aquatic vertebrates. Am. Zool. 24:107-120.

Wellborn GA, Skelly DK, Werner EE, 1996. Mechanisms creating community structure across a freshwater habitat gradient. Annu. Rev. Ecol. Syst. 27:337-363.

Werner EE, Anholt BR, 1993. Ecological consequences of the trade-off between growth and mortality rates mediated by foraging activity. Am. Nat. 142:242-272.

Werner EE, Gilliam JF, 1984. The ontogenetic niche and species interactions in size-structured populations. Annu. Rev. Ecol. Syst. 15:393-425.

Werner EE, Gilliam JF, Hall DJ, Mittelbach GG, 1983. An experimental test of the effects of predation risk on habitat use in fish. Ecology 64:1540-1548.

Williams RJ, Anandanadesan A, Purves D, 2010. The probabilistic niche model reveals the niche structure and role of body size in a complex food web. PLoS ONE 5:e12092.

Williams RJ, Martinez ND, 2000. Simple rules yield complex food webs. Nature 404:180-183.

Williams RJ, Purves DW, 2011. The probabilistic niche model reveals substantial variation in niche structure of empirical food webs. Ecology 92:1849-1857.
Williamson CE, 1993. Linking predation risk models with behavioral mechanisms: identifying population bottlenecks. Ecology 74:320-331.

Winemiller KO, 1991. Ecomorphological diversification in lowland freshwater fish assemblages from five biotic regions. Ecol. Monogr. 61:343-365.

Winemiller KO, 2007. Interplay between scale, resolution, life history and food web properties, p. 101-126. In: N. Rooney, K.S. McCann and D. Noakes (eds.), From energetics to ecosystems: the dynamics and structure of ecological systems. Springer.

Wirtz KW, 2012. Who is eating whom? Morphology and feeding type determine the size relation between planktonic predators and their ideal prey. Mar. Ecol.-Progr. Ser. 445:1-12.

Wissinger SA, 1988. Effects of food availability on larval development and inter-instar predation among larvae of Libellula lydia and Libellula luctuosa (Odonata: Anisoptera). Can. J. Zool. 66:543-549.

Woodward G, 2009. Biodiversity, ecosystem functioning and food webs in fresh waters: assembling the jigsaw puzzle. Freshwater Biol. 54:2171-2187.

Woodward G, Hildrew AG, 2002. Body-size determinants of niche overlap and intraguild predation within a complex food web. J. Anim. Ecol. 71:1063-1074.

Woodward G, Speirs DC, Hildrew AG, 2005. Quantification and resolution of a complex, size-structured food web. Adv. Ecol. Res. 36:85-135.

Woodward G, Warren PH, 2007. Body size and predatory interactions in freshwater: scaling from individuals to communities, p. 97-117. In: A.G. Hildrew, D. Raffaelli and R. Edmonds-Brown (eds.), Body size: the structure and function of aquatic ecosystems. Cambridge University Press.

Yates GT, 1986. How microorganisms move through water: the hydrodynamics of ciliary and flagellar propulsion reveal how microorganisms overcome the extreme effect of the viscosity of water. Am. Sci. 74:358-365.

Yodzis P, 1981. The stability of real ecosystems. Nature 289:674-676. 